\title{
Impact of Short-term Training in Social Cognition in Preschoolers with Externalizing Behavior
}

\author{
Marine Houssa ${ }^{1}$, Emilie Jacobs ${ }^{1}$, Nathalie Nader-Grosbois ${ }^{1}$ \\ ${ }^{1}$ Université catholique de Louvain, Psychological Sciences Research Institute, Chaire Baron Frère en orthopédagogie \\ Correspondence: Nathalie Nader-Grosbois, 10, Place Cardinal Mercier, Louvain-la-Neuve, Belgium.
}

Received: August 18, 2016

Accepted: September 26, 2016

Online Published: December 15, 2016

doi:10.11114/jets.v5i1.2081

URL: http://dx.doi.org/10.11114/jets.v5i1.2081

\begin{abstract}
In two experimental and exploratory studies, we wanted to test the differentiated effects on preschoolers with externalizing behavior (EB) of two short-term social information processing (SIP) and Theory of Mind (ToM) training sessions, in comparison with typically developing (TD) preschoolers or with preschoolers with EB whom didn't receive training. Firstly, nineteen preschoolers presenting a high level of EB problems took part in a pre-test session involving direct cognitive and socio-cognitive measures (assessing the understanding of emotions, beliefs and social problem-solving). They were then allocated at random to two experimental groups (ToM or SIP training) and compared to nineteen TD preschoolers who followed the same procedure. Four experimental groups, EB-ToM group $(n=9)$, TD-ToM group ( $n=9)$, EB-SIP group $(n=10)$, TD SIP-group $(n=10)$, received short training sessions, which were given by group of three children. All children took part in a post-test session. Secondly, EB-ToM group $(n=9)$ and EB-SIP group $(n=10)$ was compared to a control group of preschoolers with EB problems $(n=9)$. These preschoolers took part in pre-test and post-test sessions. Firstly, we tested whether the effectiveness of the training was specific to children with EB compared to TD children. Although improvement was obtained in typically developing children, larger improvements were found in the population with EB. Secondly, we compared the potential transfer of learning between the two types of experimental training in children with EB problems. Results showed some improvement in ToM and in SIP for both experimental groups. These studies provide some guidelines for training in social cognition aimed at preschoolers who are at risk of or have developed EB disorders.
\end{abstract}

Keywords: theory of mind, social problem-solving, training, preschoolers, externalizing behaviors

\section{Introduction}

At preschool age, externalizing behavior (EB) is the most common problem. The relation between individual (e.g., cognition) or environmental (e.g., parenting) factors and EB (aggressiveness, agitation, disobedience, impulsiveness or opposition) have especially been documented (Roskam, Meunier, Stievenart, \& Noël, 2013). Particularly for individual factors, a high level of EB has generally been associated with dysfunctions in social cognition and in particular with deficits in the understanding of mental states and of social problem-solving situations (Deneault \& Ricard, 2013; . Denham, Zinsser, \& Bailey, 2011; Pettit, Dodge, \& Brown, 1988; Yoon, Hughes, Gaur, \& Thompson, 1999). Because EB is a predictor of antisocial behavior, social maladjustment and mental health problems in later years, there is a clear need to detect and address it at early stage, as during the preschool period (Campbell, 2006; Faivre et al., 2005). Indeed, Roskam and collaborators (2013) in their study on the impact of child and family risk factors on EB, provide some relevant information to propose efficient intervention focusing on young children and incurring notably social cognition components.

Social cognition corresponds to the mechanisms leading to social behaviors which, in turn, are the foundation of social adjustment evaluated by others (Crick \& Dodge, 1994). Social cognition abilities allow identifying, thinking about, producing and regulating emotions; solving interpersonal problems; taking other's perspectives, beliefs and intentions (Yeates, Dennis, Rubin, Taylor, Bigler, et al., 2007). It is known that strong social cognition abilities are likely to result in adequate social adjustment and positive interactions (Yeates et al., 2007). Those abilities develop primarily between 4 and 6 years of age; in this period, children's behavior and thought processes are still flexible (Webster-Stratton, Reid, \& Beauchaine, 2011). Several approaches have been developed to explain the development of social cognition in children in development, education, clinic and communication (for more details, see Crick and Dodge, 1994). In developmental 
psychology, there are notably the Theory of Mind (ToM) models, which are based on a developmental-structural approach of the understanding of mental states of people by children, and the social information processing (SIP) model, based on a functional approach of cognitive steps mobilized by children in social critical situations. In the current study, we focused on these two models.

According to the ToM model, preschoolers develop the ability to understand their own and other people's mental states, to take other people's perspective, and to infer what they know, believe, or feel (Deneault \& Ricard, 2013; Denham \& Burton, 2003; Denham et al., 2011; Flavell, 1999; Wellman, 1991). Empirical studies have shown that children who are good at identifying and understanding other people's emotions interact successfully with them and have good social adjustment (Cutting \& Dunn, 1999; Deneault \& Ricard, 2013;- Denham et al., 2003; Nader-Grosbois, Houssa, \& Mazzone, 2013). When children are able to take other people's perspective and to infer and understand others' beliefs, they can adjust their own behavior in social situations. In studies focusing on ToM development in children with EB, deficits have been found in the recognition of emotions (Blair \& Coles, 2000; Marsh \& Blair, 2008; Speltz, DeKlyen, Calderon, Greenberg, \& Fisher, 1999) and in the understanding of the causes and consequences of emotions (Hughes, Dunn, \& White, 1998). Other authors have observed deficits in the understanding of beliefs and false beliefs in children with EB (Fahie \& Symons, 2003; Renouf et al., 2010; Walker, 2005). These deficits impact social adjustment (Eisenberg et al., 1997).

The SIP model (Crick \& Dodge, 1994) considers how, from preschool age, children become progressively able to think about social problems, and their ability to solve them gradually leads to increasingly efficient social reasoning (Dodge \& Pettit, 2003; Fontaine \& Dodge, 2009). Five steps have been identified that children mobilize when acting in a social situation. Firstly, they encode other people's social cues (step 1) and interpret those social cues (step 2) before clarifying goals (step 3). After this, they access or construct responses (step 4), and finally, they make a response decision (step 5) (Crick \& Dodge, 1994). Deficits in EB children have been postulated in each of these five steps of SIP (Crick \& Dodge, 1994; Dodge \& Crick, 1990; Dodge \& Pettit, 2003) and as getting worse with time (Dodge et al., 2003). Concretely, in critical social situations (i.e., provocation), children can have difficulties in identifying social cues (1), in interpreting them (2), and in attributing intentions accurately, or distinguishing good from bad (3). They may also consider less prosocial responses (4) or have a more favorable attitude towards responding aggressively (5) (for a review, see $\mathrm{Li}$, Fraser, \& Wike, 2013). Moreover, as aggressive children are likely to be rejected by their peers, they have less opportunity for positive social interactions (Crick \& Dodge, 1996). In summary, deficits in social cognition may contribute to the development of EB disorders in children (Dodge et al., 2003; Runions \& Keating, 2007; Yoon et al., 1999).

Even if those two models share some common characteristics, as like both allow highlighting individual differences involved in social adjustment and both are based on social knowledge (Crick \& Dodge, 1994; Repacholi, Slaughter, Pritchard, \& Gibbs, 2003), several elements distinguish them. Firstly, the explicative nature of each model differs because the ToM model is a developmental process while the SIP model is a functional one. The ToM model does not explain in detail the way children deal with mental states at same time, but gives explanations about the way the reasoning became more and more complex (Wellman, 1991). For its part, the SIP model clarifies how social reasoning happens, moment by moment (Crick \& Dodge, 1994). Secondly, the target of each model is different. The ToM model is interested in what oneself or others can feel, think or believe differently. On a developmental plan, a child can understand firstly one mental state and secondly several, even combination of these. In fact, there are different degrees of complexity in ToM. Regarding the SIP model, it allows to understand the way in which we decode others intentions in critical social situations (i.e., provocation or ambiguous situations). The ToM competences allow to take other's and self's perspective, which is not the case of SIP competences because with those, the child adapt himself to what happens in his environment in response to a social situation.

With a view to improve socio-cognitive skills, studies have been conducted to test the potential effectiveness of short term training in the understanding of mental states for preschoolers (Melot \& Angeard, 2003), for children with intellectual disabilities (Sweettenham, 1996) or for autistic children (Gevers, Clifford, Mager, \& Boer, 2006; Hadwin, Baron-Cohen, Howlin, \& Hill, 1996). Some studies have reported positive effects from these training sessions related to ToM, using materials such as puppets, emotion cards, interactive games, stories, interactions focusing on mental states, etc. Children's performance in ToM tasks improved after training in understanding emotions (Walker, 2005) or in understanding false beliefs in various conditions. The techniques used included conversations, explanations of correct responses, differentiated immediate feedback on performance, discussion of scenarios related to emotions and beliefs, and the generalization of concepts (Amsterlaw \& Wellman, 2006; Appleton \& Reddy, 1996; Clements, Rustin, \& McCallum, 2000; Howlin, Baron-Cohen, \& Hadwin, 2011; Kloo \& Perner, 2003).

To our knowledge, no study has ever investigated the impact of short-term SIP training in social problem-solving for typically developing (TD) preschoolers or preschoolers with EB disorders. SIP training usually takes the form of 
medium and long-term interventions, with the goal of improving abilities in social problem-solving and abilities at generating alternative solutions in critical social situations. An improvement in social problem-solving was obtained after an intervention in which children talked about stories of peer interaction and performed related activities (Bhavnagri \& Samuels, 1996), but also after children had taken part in role-playing games (using videos, pictures, posters, critical social situations, etc.) (Shure \& Spivack, 1982; Webster-Stratton et al., 2011). These techniques are quite similar to those using in ToM training (discussions, explanations, immediate feedback and concept generalization), except that they refer to critical social situations.

In a preliminary experimental study, Houssa, Nader-Grosbois, and Jacobs (2014) examined the respective effects of one-shot ToM and SIP trainings separately in TD preschoolers. After a 45-minute training session, the ToM experimental group had improved their abilities in ToM-emotions and in social problem-solving significantly more than the control group, while the SIP experimental group improved significantly their abilities in social problem-solving and also in ToM-beliefs.

Based on these results and on the literature reported above, we know that SIP and ToM abilities are 'trainable' and that they potentially interact with each other. But no study has ever combined structural-developmental (ToM) and functional (SIP) approaches in order to investigate the respective effects of one-shot ToM and SIP training sessions on socio-cognitive abilities in preschoolers with EB. Through two studies, we tested whether preschoolers with EB can become more sensitive and conscious about emotional cues in order to understand others' feelings and mental states (ToM) and about social cues in order to solve social problems after one-shot training sessions in ToM or SIP. Concretely, during these sessions, as Houssa et al. (2014), the comprehension of emotions and beliefs was stimulated through stories, cartoons extracts and pictures in ToM training, while in SIP training, we stimulated social problem-solving abilities by using stories and videos about critical social situations.

The objectives of the studies were, firstly, without hoping a long-term effect or a reduction of EB level, we tested whether performance in social cognition tasks can be improved through short stimulations in TD or EB preschoolers. In particular, through the comparison of TD and EB children (receiving ToM or SIP training), we wanted to know whether children could be more sensitive to mental states (ToM) and to social problems abilities after one-shot training sessions in ToM or SIP and whether one population would benefit more than the other from the training. This could be useful for professionals to know which materials and techniques are specifically efficient to train ToM, SIP and social cognition competences in preschoolers with EB. We predicted that the training would have a greater effect on the population with EB than on the TD population. To do this, we compared our results with the results of M. Houssa et al. (2014) because the same design, training material and techniques were used. Consequently, the results will be discussed in comparison to those of Houssa et al. (2014). Secondly, we tested the efficiency of the training (in ToM or SIP) with preschoolers with EB through a paired approach. In comparison with a control group, we compared the potential transfer of learning to other social cognition skills between the two types of experimental training in the population with EB; in other words, we assessed the differentiated effects of two types of training (ToM or SIP) on the level of social cognition skills in preschoolers with EB. As regards results obtained by Houssa et al. (2014), we predicted that children who received ToM training would improve their SIP abilities in post-test and children who benefited from SIP training would improve their ToM abilities in post-test. As explained in the introduction, even if those models are distinguished by some elements both are based on social knowledge and are able to highlight individual differences in social adjustment (Crick \& Dodge, 1994; Repacholi et al., 2003).

\section{Method}

\subsection{Participants}

Firstly, the participants were 19 children with EB (15 boys and 4 girls) and 19 TD children (12 boys and 7 girls), matched for sex and developmental age. Matching the children for global developmental age (GDA) allowed us to control for verbal and nonverbal developmental age, which is crucial because of its potential impact on social cognition development. In consequence of the matching on GDA, the CA of the EB group could be higher than that of the TD group.

Children with EB were between 4 years and 4 months and 7 years and 5 months old $(M=74.32$ months, $\mathrm{SD}=11.69)$, and the mean GDA was about 4 years and 6 months $(M=54.24, \mathrm{SD}=11.12)$. The TD children were between 3 years and 9 months and 5 years and 4 months old $(M=54.16, \mathrm{SD}=4.94)$ and their GDA was around 4 years and 9 months $(M$ $=57.46, \mathrm{SD}=9.38)$. The level of parents' education was also measured. The majority of mothers and fathers of TD children has a high level of education: either graduate school (25\% of fathers, $37.5 \%$ of mothers), or university level (56.3\% of fathers, $50 \%$ of mothers). Whereas parents of the children with EB have a lower level of education; either apprenticeship (50\% of fathers, $28.6 \%$ of mothers), or graduate school (only for $42.9 \%$ of mothers).

Secondly, to test the efficiency of the training with preschoolers with EB, we recruited 9 children with EB, in addition 
to the 19 children with EB, from experimental groups. These 28 children ( 22 boys and 6 girls) with EB were between 3 years and 3 months and 8 years and 9 months old $(M=72.54, \mathrm{SD}=13.83)$ and the mean GDA was about 4 years and 7 months $(M=55.05, \mathrm{SD}=12.76)$. The level of mothers' education was mostly corresponding to a short higher education $(46.2 \%)$, while for fathers, it corresponds to an apprenticeship (20\%) or to secondary school (30\%).

All children were recruited in French-speaking Belgian schools. Their teachers identified children who met the inclusion criterion of elementary comprehension and production of spoken French. TD preschoolers were in ordinary preschool classes whereas the children with EB had been evaluated (through standardized assessments like the Child Behavior Checklist; Achenbach, 1991) by psycho-medico-social centers' professional for children oriented in special classes adapted, or by us for children of ordinary schools with therapeutic care. There is no difference regarding GDA between children with EB integrated in ordinary schools $(M=46.60, \mathrm{SD}=10.88)$ and those in special issues $(M=$ $56.89, \mathrm{SD}=12.59)(t(27)=1.69, p=.10)$. Children were excluded if they showed developmental delay or intellectual disabilities. Information letters and consent forms for the child's participation were completed by parents and returned.

\subsection{Instruments}

\subsubsection{Differential Scales of Intellectual Efficiency-Revised (EDEI-R, Perron-Borelli, 1996)}

These scales were used to check that children had verbal and non-verbal developmental ages between 3 years and 6 years 6 months, in order to be included in the sample. The VDA was obtained by means of scores in "knowledge" and "social understanding" scales, and the non-verbal developmental age by means of "practical adaptation". As regards validation, the correlations calculated between the raw scores of all scales were high: they varied between .47 and .88 ; half of the scores were .70 or below.

\subsubsection{ToM-emotions tasks (Nader-Grosbois \& Thirion-Marissiaux, 2011)}

This measure is divided in three tasks. (1) Preliminary task of facial emotional expression (FEE) recognition. The four basic emotions (joy, sadness, anger, and fear) were illustrated by pictures and had to be recognized by the child. (2) Causes of emotions task. This task involved four similar beginnings of scripts ("three friends go on a picnic in the forest"). The end of each script varied in order to elicit an appropriate response according to the emotional coloring in the script: joy (friends eat picnic); anger (picnic is ruined by two friends); sadness (picnic cancelled because of rain); fear (fierce dog approaches the picnic). After reading the script of the four FEEs, the experimenter asked the participant to assign an emotion to the protagonist. According to the emotion assigned and the participant's justification, the response to each script was scored between 0 and 1.5 points $(0=$ false FEE, no or incoherent justification; $0.5=$ false FEE, coherent justification; 1 = correct FEE, no or incoherent justification; $1.5=$ correct FEE, coherent justification). The maximum score was 6 points. (3) Consequences of emotions task. Four scripts were illustrated by two pictures, each including: joy (receiving a gift); anger (conflict between friends); sadness (a pet's death); and fear (imagining monsters in bedroom at night). After explaining the beginning of the script, the experimenter asked the child to infer the protagonist's behavior. In order to do so, the child had to choose one of three pictures illustrating socially adjusted, maladjusted or neutral behavior and to justify his or her choice. According to this choice and the participant's justification, the response to each situation was scored between 0 and 1.5 points $(0=$ socially maladjusted or neutral behavior, non-justified or incoherent justification; $0.5=$ socially maladjusted or neutral behavior, coherent justification; $1=$ socially adjusted behavior, non-justified or incoherent justification; $1.5=$ socially adjusted behavior, coherent justification). The maximum score was 6 points. The two ToM-emotions tasks were scored out of a combined total of 12 points.

A computer version of these tasks was used in this study. The factor analysis revealed two subscales (causes and consequences) which were found in the original version. Cronbach's alpha was .57 , and the test-retest stability was highly significant for the two subscales (between .56 and .68).

\subsubsection{ToM-beliefs Tasks (Nader-Grosbois \& Thirion-Marissiaux, 2011)}

These five tasks were used to estimate the understanding of beliefs: (1) Deception skills test (Oswald \& Ollendick, 1989): The experimenter hid an object in one hand, and the child then did likewise. The experimenter noted whether or not the child really hid the object. (2) Change of representation task (Flavell, Everett, Croft, \& Flavell, 1981): The experimenter was sitting opposite the child with a picture of a turtle placed between them, and the child was asked: "What do you see?" and "What do I see?" (3) Appearance-Reality task (Flavell, 1986): Substitute objects were presented (e.g., a flashlight in the shape of a mobile phone) and the child was asked two questions: "If you look at this object and you don't touch it, what does it look like?" and "What is it really?" (4) Unexpected content task (Perner, Leekam, \& Wimmer, 1987): The child was shown a Smarties box and the experimenter asked: "What is inside the box?" The child then opened the box and found pencils. The pencils were returned to the box and the child was asked: "What did you think was in the box before it was opened?" and "What will your mother think is in the box if she has not seen 
inside it?" (5) Change of location task (Wimmer \& Perner, 1983): This corresponds to the "Max and the transfer of chocolate" task.

These ToM-beliefs tasks were scored out of a total of 5 points ( 1 point for each task). For the validation, the inter-judge agreement was very high (agreement percentage between $99 \%$ and 100\%; Cohen's kappa between .98 and .99; Pearson correlation coefficient between .99 and 1). No difference between the test and retest session was obtained.

As ToM-emotions task, ToM-beliefs tasks were validated with children with atypical development (Nader-Grosbois, 2011) and allowed notably to discriminate children with impaired ToM as children with intellectual disabilities or children with EB (Nader-Grosbois et al., 2013).

\subsubsection{Social problem-solving Task (RES, Barisnikov, Van der Linden, \& Hippolyte, 2004)}

This task was used to estimate the capacity of the children to judge whether or not, other people's social behavior was appropriate, and to determine the extent to which their judgment was based on knowledge of conventional and/or moral rules. The task consisted of showing subjects 14 pictures, presenting five appropriate and nine inappropriate social behaviors displayed by a character in social situations, taken from everyday life. The RES score could distinguish between appropriate and inappropriate behaviors. For each item, the child was firstly asked whether the social behavior was appropriate or not; the maximum score here was 28 points (judgment score). The second question assessed the capacity of the child to identify the target behavior; the maximum score here was 14 (identification score). Finally, the third question (reasoning score) estimated the extent to which the judgment was justified by reference to social rules. Three levels of response were offered for this question, corresponding to the award of 2, 5, and 7 points respectively. First, the descriptive level corresponded to a justification in which the child merely described the illustrated situation (e.g. "she is pulling the girl's hair"). Second, the inter-subjective level corresponded to an explanation which reflected a position linked to social consciousness but limited to an understanding of concrete aspects of the situation ( e.g. "she is pulling her hair and it hurts"). Third, the conceptual level reflected social consciousness, a reference to social rules, and generalization (e.g. "it is not good to hurt somebody else"). No points were given if a justification was not given, was inappropriate or reflected a misunderstanding of the situation. The maximum score for this third question was 98, and 140 for three questions in 14 items. The validation was performed with typically developing children and children with intellectual disability. The inter-judge agreement was $98 \%$ congruent (Hippolyte, Iglesias, Van der Linden, \& Barisnikov, 2010).

\section{Procedure}

The research consisted of three phases: pre-test, training and post-test. For the pre-test session, four different tests were initially administered across two sessions for each participant (lasting 30 to 45 minutes according to the participant's attention and availability). The tests were: EDEI-R scales, ToM-emotions and beliefs tasks, and RES. Total administration time was approximately 70 minutes. All tests were administered individually in counterbalanced order and in a quiet room. Then, children were randomly assigned to one of the experimental groups (ToM or SIP training groups) or to the control group. Consequently, there were 9 TD children and 9 EB children in ToM-training groups; 10 TD children and 10 EB children in SIP-training groups; and 9 EB children in the control group. In subgroups of three or four children, they participated in a training or free play session for 45 minutes and finally, they were assessed in a post-test session for 45 minutes, by means of ToM-emotions and beliefs tasks and RES. There was an interval of 2-4 days between pre- and post-tests. A summary report on the participants' abilities was sent to their parents and teachers.

\subsection{ToM Training Experimental Group}

The goal was to stimulate the comprehension of emotions and beliefs, based on the program conceived by Howlin et al. (2011), who described five developmental levels of these abilities. Each component was divided into five successive levels. These levels and the acquisition criteria for the understanding of emotions were: (1) photographic facial recognition, (2) schematic facial recognition, (3) situation-based emotions, (4) desire-based emotions, (5) belief-based emotions. For the understanding of beliefs, the levels were: (1) simple perspective taking, (2) complex perspective taking, (3) seeing leads to knowing, (4) true belief/action prediction, (5) false belief (Hadwin et al., 1996).

Before the session, each child received four pictures of faces representing the expression of the four basic emotions, because correct recognition was necessary to begin the training. The first part used the material and program design of Howlin et al. (2011).

The second part included the presentation of cartoon extracts where the protagonist was in a situation eliciting joy, sadness, anger or fear, or had a false belief. The purpose of these two first parts was to train the child to understand the causes and consequences of emotions and some aspects of beliefs, such as reporting another person's false beliefs.

The third part featured the game "Mental Simil" (Juarez Monfort, Juarez Sanchez, \& Monfort, 2009) presenting a series of pictures illustrating stories featuring false beliefs. The experimenter showed the pictures one by one and told the story. 
The child had to explain and talk about the featured false beliefs. Across the session, the experimenter used immediate feedback and generalized concepts (e.g., "When something unpleasant happens accidently or when someone leaves, you feel sadness").

For each vignette, the children had to say or point to the protagonist's emotion, and at the end of each situation they had to reply to some questions about the protagonist's emotions, desires and beliefs and to justify their choice. Questions were asked such as, "How does Suzanne feel when her father has to leave?" and "Why does she feel like that?". If the child gave a correct reply, the experimenter reinforced and consolidated this reply. By contrast, if the response was incorrect, the experimenter gave the correct reply and explained it.

These questions were supposed to help the child to understand mental states. Finally, the experimenter made links with their life experience. This question was intended to encourage the generalization of the concepts involved.

\subsection{SIP Training Experimental Group}

The objective was to stimulate the social problem-solving abilities, based on the steps of the SIP model (Crick \& Dodge, 1994). As described above, this functional approach describes five steps in helping children to think about and resolve social problems: (1) encoding other people's social cues, (2) interpreting social cues, (3) clarifying goals, (4) accessing responses and (5) deciding on a response.

The SIP training session used two sets of materials: stories illustrating social situations with bears from the "Social Information Processing Interview for Pre-schoolers" (SIPI-P, Ziv \& Sorongon, 2011) and video-based SIP illustrating social situations from the "Schultz Test of Emotion Processing-Preliminary Version" (STEP-P, Schultz et al., 2010).

More precisely, three stories from SIPI-P illustrating critical social situations with teddy bears were presented to the children, and nine videos from STEP-P were shown, illustrating situations of "provocation", "goal acquisition" and "emotions". The provocation category contained videos in which a child received provocation, but the provoker's intentions were unclear. The goal acquisition category contained videos in which children attempted to attain a goal. The emotions category contained videos in which either an emotion-eliciting event occurred or a child displayed emotion-related behavior (Schultz et al., 2010). Each child in the SIP group was presented with one story from SIPI-P and three videos from STEP-P.

At the end of each story or video, the experimenter questioned the child to check if he/she understood what had happened and asked if he/she could explain it. The experimenter then asked some questions such as "How will X react?", "Is it a good thing or a bad thing for X to do that?" and "If you did that, do you think the other child would like you?"

These questions were supposed to help the child to identify the social cues, to indicate whether a protagonist had acted deliberately, and to predict the verbal and non-verbal behavior of the protagonists. Finally, the experimenter asked the child whether he/she had had a similar experience him/herself, and how he/she had or would have reacted. As in ToM training, this question was intended to encourage the generalization of the concepts involved.

\section{Results}

\subsection{Comparison of Our Results with the Results of Houssa et al. (2014)}

Within each training condition (ToM or SIP training), we tested whether EB and TD children differed concerning individual characteristics. Subsequently, we calculated independent sample $t$-tests on the training effect (progression between pre- and post-test in each case) to see whether, through a group comparison approach, the effectiveness of the training was different between EB and TD children.

\subsubsection{Between-group Comparisons in Pre-test}

As Table 1 shows, the two ToM groups (EB and TD children) did not differ for sex and GDA, however significant differences were obtained for chronological age (CA) and mothers' and fathers' level of education. The two SIP groups (EB and TD children) likewise did not differ for the GDA, but they differed significantly for CA and fathers' level of education, while the differences about mothers' level of education and sex were marginally significant. In both training conditions (ToM and SIP groups), the TD children were younger than the children with EB. Furthermore, the mothers and fathers of TD children had on average a higher level of education than the mothers and fathers of children with EB. Finally, the difference for sex in the SIP group was nearly significant. It's due to the fact that, in SIP-training groups, the EB group included exclusively boys, whereas in the TD group, there were three TD girls.

\subsubsection{Comparisons of Progression between TD and EB Groups}

Concerning ToM training, Independent sample $t$-tests on the progression between pre- and post-test in ToM and SIP measures did not show a difference (see Table 2). Looking in greater detail at the SIP measure, we were able to 
differentiate the results in terms of appropriate versus inappropriate items (because the RES score could distinguish between appropriate and inappropriate behaviors). Concerning the children's responses in regard to this distinction, while in the pre-test there was no difference, in the post-test, a difference, between EB and TD groups, on judgment score (Question 1) related to inappropriate social behaviors approached nearly the significance. In fact, the EB group $(M$ $=17.33, \mathrm{SD}=1.00)$ showed a better judgment score (Question 1$)$ on inappropriate social behaviors $(t(16)=2.00, p$ $=.06)$ than the $\mathrm{TD}$ group $(M=16.00, \mathrm{SD}=1.73)$.

Concerning SIP training, Independent sample $t$-tests on the progression between pre- and post-test did not show a difference in the training effect in ToM and SIP measures, except for the reasoning score of the RES (Question 3) for which the difference was marginally significant. The training seemed to have a greater effect on the EB group than on the TD group for this question. Within the reasoning score of the RES, this difference remained nearly significant only for the most complex level of justification (conceptual level). The comparison of the efficiency of the training for EB and TD groups was nearly significant; in the sense that the EB group would benefit more from the training than the TD group, $t(18)=1.96, p=.06$.

In the RES, whereas in the pre-test there was no difference between groups, in the post-test, the EB group $(M=50.30$, $\mathrm{SD}=14.47)$ had better skills in social problem-solving concerning inappropriate behavior $(t(18)=2.15, p=.004)$ than the TD group $(M=39.30, \mathrm{SD}=7.18)$. More specifically, we observed differences between the TD and EB groups on reasoning scores (Question 3) for inappropriate social behaviors. The EB group $(M=25.20, \mathrm{SD}=11.71$ ) had a significantly better score $(t(18)=2.40, p=.003)$ than the TD group $(M=15.80, \mathrm{SD}=4.05)$. The TD group never used the conceptual level in post-test, whereas almost the half of children (44\%) from the EB group used this level of justification once or more than once.

\subsection{Efficiency of the Training with preschoolers with EB}

One-way ANOVAs and $\mathrm{Chi}^{2}$ tests were conducted to check the equivalence between groups (ToM, SIP and control groups) in pre-test. Then, to measure the effectiveness of the training, a paired approach (paired sample $t$-tests) was conducted with pre- and post-test scores in each case as a within-group measure.

\subsubsection{Pre-test and Post-test Performance}

Table 3 presents the means and standard deviations for all variables in the pre-test session. Analyses revealed no significant difference between the three EB groups (ToM, SIP and control groups). About sex; the difference is marginally significant between groups (the SIP group was 100\% boys, while the ToM group was $70 \%$ boys and the control group was $78 \%$ boys).

\subsubsection{Effect on ToM Abilities in EB Groups}

A one-way ANOVA on the progression of the three groups (ToM, SIP and control groups) was conducted on the ToM-emotions performance. This analysis revealed no significant effect, $F(2)=.88$ for total score of the ToM-emotions, either for causes, $F(2)=1.53$ or for consequences of emotions, $F(2)=.22$.

A one-way ANOVA on the progression of the three groups was also conducted on performance in ToM-beliefs, and revealed that the difference between groups was marginally significant, $F(2)=2.70, p=.09$. Furthermore, the one-sample $t$-tests showed that there is a significant difference between the control group and the SIP group $(t(18)=$ 2.23, $p=.04)$, and a difference nearly significant between the control group and the ToM group $(t(17)=2.06, p=.06)$.

In Table 4, paired sample $t$-tests showed a pre-/post-test effect, significant or marginally significant, in the ToM and SIP groups for both ToM measures. For ToM-emotions in particular, the ToM group improved in post-test in their performance with regard to causes of emotions, whereas the SIP group improved in post-test with regard to consequences of emotions. Furthermore, in ToM-beliefs, the difference of ToM group's performance between pre- and post-tests was marginally significant, while the performance of SIP group increased significantly after the training.

\subsubsection{Effect on SIP Abilities in EB Groups}

In Table 4, paired sample $t$-tests showed a pre-/post-test effect in both experimental groups for the social problem-solving task. The control group's performance did not increase in post-test, whereas the ToM and SIP groups had better scores after the training. In particular, the percentage of "wrong or no justification" decreased significantly in both of these experimental groups (i.e. they offered fewer wrong justifications and failed to give any justification less often), but not in the control group. Furthermore, children in the SIP group increased their score by giving a justification to their response using the conceptual level but this increasing is marginally significant.

Next, a one-way ANOVA on the progression of the three groups was conducted on the RES total score and sub-scores. This analysis revealed no significant effect for the RES total, $F(2)=2.30$, either for Question $1(F(2)=.86)$ or for Question $2(F(2)=1.72)$. However, this analysis revealed a difference for Question 3 nearly significant $(F(2)=2.97, p$ 
$=.07)$. However, the one-sample $t$-tests showed a significant difference between the control group and the SIP group $(t(17)=2.27, p=.04)$, but also between the control group and the ToM group $(t(16)=2.46, p=.02)$.

\section{Discussion}

\subsection{Comparisons of Progression between TD and EB Preschoolers, after Training}

As a reminder, the goal of this exploratory study was neither to change social cognition or EB level after one training session, nor to obtain a long term-effect, but rather to study the potential modifiability of social cognition competences in preschoolers with EB. By a comparison with Houssa et al. (2014) study, we also wanted to know whether one population (TD or EB) would benefit more than the other from the training. Our prediction about the specificity of the training effect depending on the population was partially confirmed. We cannot state that children with EB benefit more from ToM training than TD children, because we found no difference in the training effect between groups. Nevertheless, we observed differences between the populations after the SIP training: concerning reasoning score in the RES, children with EB increased more than TD children. More particularly, children with EB offered more accurate explanations of inappropriate behaviors. While none of the TD children used the conceptual level, almost half of the children with EB did so at least once, meaning that they were beginning to step back from the context and generalize to a social rule (Barisnikov et al., 2004).

Concerning social problem-solving abilities, although it has been established that children with EB have difficulties in these type of tasks (Crick \& Dodge, 1996), our results, as those of Nader-Grosbois et al. (2013), showed that, when they are matched for GDA, children with EB and TD children have similar results. On this basis, even if children with EB have some competences in social problem solving, they seemed to be more receptive and sensitive to our SIP training than TD children matched for GDA. This could be explained by the fact that our intervention aimed at changing children's representational system. In fact, Yoon et al. (1999) explained in their meta-analysis on social cognition in children with EB that deficits and distortions in SIP can be a manifestation of maladaptive representational systems. Consequently, they conclude that trainings which do not change this representational system will show effects size limited and only short-term efficacy.

\subsection{Efficiency of the Trainings in Preschoolers with EB}

Secondly, through the analysis of the efficiency of the training with preschoolers with EB, we wanted to evaluate the potential transfer of learning in preschoolers with EB after two types of training (ToM and SIP). Our predictions were confirmed because we observed some improvements in ToM and SIP performance in both experimental groups. We showed that training with feedback and explanations improved performance in social cognition. As expected, ToM training led to improvements in understanding of emotions and beliefs, while SIP training led to improvements in social problem-solving. As Houssa et al. (2014) found with TD children, training not only improved performance in the skills concerned, but also induced a transfer of learning to other social cognition skills. ToM training also led to improvements in social problem-solving, while SIP training fostered understanding of emotions and beliefs, meaning that children learned something that went beyond the context of the task (Kloo \& Perner, 2003).

As we know, when children are able to understand beliefs, they can see things from other people's cognitive perspective and adjust their own behavior as a consequence (e.g., Flavell, 1999), the fact that the ToM group improved their skills in social problem-solving is therefore not surprising. Moreover, approaching the understanding of mental states through social situations (stories, cartoons, etc.) could enhance their ability to interpret other people's behavior (Bhavnagri \& Samuels, 1996).

Like Houssa et al. (2014) in the case of TD children, we found a transfer of learning for the understanding of beliefs in EB children: the SIP group's understanding of beliefs had improved after the training. But contrary to Houssa et al. (2014), who found no improvement in ToM-emotions for the SIP group, in our study the SIP group showed an increased understanding of the consequences of emotions. This surprising result could be due to the fact that we addressed learning about social cues in critical social situations in the SIP training. These cues could be emotional, leading the child to choose adequate behaviors to a situation and be reflected in ToM tasks; as in the SIP training, we learned to choose the best solution for a critical social situation, and children were able to transpose this competence in the choice of socially adjusted behavior (in the ToM-emotions). This surprising result could also be due to an impact of the training on social adjustment because the literature shows links between social adjustment and ToM or SIP (Crick \& Dodge, 1994; Nancy Eisenberg, Cumberland, \& Spinrad, 1998; Yeates et al., 2007). Unfortunately, we did not include a measure of social adjustment but it could be relevant in future studies.

In the study of Houssa et al. (2014), a greater impact was found after the ToM training than after the SIP training. The authors explained this difference in terms of the attractiveness of the ToM training in comparison with the SIP training, which was less motivating. Nevertheless, through the comparison of our results with the results of Houssa et al. (2014), 
we showed that EB children's justifications of social problem-solving situations improved more than those of TD children after SIP training. We can therefore affirm that the effect is not linked to the attractiveness of the material, but rather to greater susceptibility to SIP training in children presenting a high level of EB. It goes to the sense of Yoon et al. (1999) who highlighted differences between TD and EB children in social cognition in a meta-analysis and told that these differences between TD and EB children has implications for clinicians because it justified an adapted training planning.

Thanks to the control group, whose performance stabilized or decreased between pre- and post-test, we know that the improvement in the two experimental groups after the training was not due to the learning effect. However, we identified a methodological bias concerning the ToM-beliefs, in fact, some subjects had already achieved the maximal score in pre-test. Due to this ceiling effect, it could be more appropriate to use another measure, such as the ToM Task Battery (Hutchins, Prelock, \& Chace, 2008), which was already used in a similar experimental design (Hutchins \& Prelock, 2006), and for which items cover the entirety of the preschool period in terms of ToM development (inhibiting ceiling effect).

In addition, it's important to point, as a limitation of the present study, the small samples; consequently, these results need to be tested and confirmed in larger samples.

In conclusion, although we cannot claim to have modified social cognition processing or reduce EB level through one training session, our results suggest that such modifications would be possible after several training sessions.

We also found that one-shot training in social cognition seems to be more effective for children with EB than for TD children. It would therefore be interesting to replicate this study in children with intellectual disabilities, as some authors have found deficits in social cognition in such children (Baurain \& Nader-Grosbois, 2013; Nader-Grosbois et al., 2013; Van Nieuwenhuijzen \& Vriens, 2012), but also to expand the sample of children with EB so as to generalize our results with stronger analysis (like regression analysis to identify the prediction factors for the results in children with $\mathrm{EB})$.

This exploratory study highlights that it is possible and relevant to work with different profiles of children with training of this kind, and that this training would work even better if children's strengths and weaknesses were first analyzed in reference to ToM and SIP competences (Yoon et al., 1999), in order to adapt the training. Furthermore, this study shows that children with EB are sensible to training which aimed at fostering socio-cognitive competences through techniques such as generalization, feedback and explanation with simple daily activities that parents and teachers can organize, such as watching cartoons or reading stories, or even when listening to children describing things that have happened to them. Another recent study tested the efficacy of a middle-term intervention combining the training of ToM and SIP competences in children with EB and showed the importance to take into account these two models of social cognition as theoretical backgrounds to orientate intervention toward these preschoolers (Houssa \& Nader-Grosbois, 2016).

Table 1. Means and standard deviation in pre-test for individual characteristics in TD and EB groups in each condition and between-group comparisons

\begin{tabular}{|c|c|c|c|c|c|c|c|c|c|c|}
\hline \multirow[b]{3}{*}{ Variables } & \multicolumn{4}{|c|}{ ToM training } & & \multicolumn{4}{|c|}{ SIP training } & \multirow[b]{3}{*}{$X^{2} / t$} \\
\hline & \multicolumn{2}{|c|}{ TD group $n=9$} & \multicolumn{3}{|c|}{ EB group $n=9$} & \multicolumn{2}{|c|}{ TD group $n=10$} & \multicolumn{2}{|c|}{ EB group $n=10$} & \\
\hline & $M(\mathrm{SD})$ & Range & $M(\mathrm{SD})$ & Range & $X^{2} / t$ & $M(\mathrm{SD})$ & Range & $M(\mathrm{SD})$ & Range & \\
\hline Sex (\% Male) & 55 & & 55 & & 00 & 70 & & 100 & & $3.53 \dagger$ \\
\hline $\mathrm{CA}$ & $\begin{array}{l}54.67 \\
(2.69)\end{array}$ & $49-58$ & $\begin{array}{l}71.44 \\
(11.98)\end{array}$ & $52-88$ & $4.10 * *$ & $\begin{array}{l}53.70 \\
(6.46)\end{array}$ & $45-64$ & $\begin{array}{l}76.90 \\
(11.42)\end{array}$ & $52-89$ & $5.59 * * *$ \\
\hline GDA & $\begin{array}{l}55.67 \\
(8.93)\end{array}$ & $46.33-76.83$ & $\begin{array}{l}52.36 \\
(11.04)\end{array}$ & $39.60-67$ & -.70 & $\begin{array}{l}59.07 \\
(9.96)\end{array}$ & $42.60-74$ & $\begin{array}{l}55.93 \\
(11.50)\end{array}$ & $36-70.33$ & .65 \\
\hline VDA & $\begin{array}{l}54.59 \\
(6.74)\end{array}$ & $41.50-64.25$ & $\begin{array}{l}48.83 \\
(9.67)\end{array}$ & $36.50-66$ & 1.47 & $\begin{array}{l}56.25 \\
(9.88)\end{array}$ & $41-72$ & $\begin{array}{l}56.25 \\
(13.74)\end{array}$ & $36-79$ & 00 \\
\hline $\begin{array}{l}\text { Mothers' } \\
\text { education (max } \\
=7 \text { ) }\end{array}$ & $\begin{array}{l}6.00 \\
(1.53)\end{array}$ & $3-7$ & $\begin{array}{l}4.00 \\
(.82)\end{array}$ & $3-5$ & $-2.39 *$ & $\begin{array}{l}5.78 \\
(1.39)\end{array}$ & $3-7$ & $\begin{array}{l}4.00 \\
(1.72)\end{array}$ & $2-5$ & $1.82 \dagger$ \\
\hline $\begin{array}{l}\text { Fathers' } \\
\text { education ( } \max \\
=7 \text { ) }\end{array}$ & $\begin{array}{l}5.71 \\
(1.38)\end{array}$ & $4-7$ & $\begin{array}{l}2.50 \\
(2.12)\end{array}$ & $1-4$ & $2.66^{*}$ & $\begin{array}{l}6.22 \\
(1.39)\end{array}$ & $3-7$ & $\begin{array}{l}3.00 \\
(1.41)\end{array}$ & $2-4$ & $2.95^{*}$ \\
\hline
\end{tabular}

Note. $\mathrm{CA}=$ Chronological Age, GDA = Global Developmental Age, VDA = Verbal Developmental Age, TD = Typically Developing, $\mathrm{EB}=$ Externalizing Behavior, ToM $=$ Theory of Mind; SIP $=$ Social Information Processing. $\uparrow p \leq .10,{ }^{*} p$ $\leq .05,{ }^{* *} p \leq .01,{ }^{* * *} p=.00$. 
Table 2. Training effects mean scores and standard deviation for TD and EB groups in each condition (ToM and SIP) and between-group comparisons

\begin{tabular}{|c|c|c|c|c|c|c|c|}
\hline & & \multicolumn{3}{|l|}{ ToM training } & \multicolumn{3}{|l|}{ SIP training } \\
\hline & & $\begin{array}{l}\text { TD group } \\
n=9\end{array}$ & $\begin{array}{l}\text { EB group } \\
n=9\end{array}$ & & $\begin{array}{l}\text { TD group } \\
n=10\end{array}$ & $\begin{array}{l}\text { EB group } \\
n=10\end{array}$ & \\
\hline Variables & & $M(\mathrm{SD})$ & $M(\mathrm{SD})$ & $t$ & $M(\mathrm{SD})$ & $M(\mathrm{SD})$ & $t$ \\
\hline \multirow{4}{*}{ ToM } & ToM-emotions-causes & $1.22(.97)$ & $1.28(1.99)$ & .24 & $.06(.88)$ & $.45(1.72)$ & .62 \\
\hline & $\begin{array}{l}\text { ToM-emotions- } \\
\text { consequences }\end{array}$ & $1.17(1.17)$ & $1.11(2.51)$ & -.12 & $.17(.90)$ & $1(1.45)$ & 1.48 \\
\hline & ToM-emotions & $2.39(1.27)$ & $2.06(3.86)$ & .04 & $.22(1.44)$ & $1.25(2.35)$ & 1.38 \\
\hline & ToM-beliefs & $.39(.49)$ & $.78(1.48)$ & 1.07 & $.80(1.08)$ & $.7(.98)$ & .00 \\
\hline \multirow[t]{4}{*}{ SIP } & RES total & $11.56(11.32)$ & $18.67(21.47)$ & .88 & $3.7(8.97)$ & $15.4(21.74)$ & 1.57 \\
\hline & RES Question 1 & $2.22(2.11)$ & 2.67 (4) & .29 & $.5(2.07)$ & $2(4)$ & 1.05 \\
\hline & RES Question 2 & $1.00(1.66)$ & $1.89(2.89)$ & .80 & $1.4(1.95)$ & $.9(2.51)$ & -.50 \\
\hline & RES Question 3 & $8.33(8.99)$ & $14.11(17.86)$ & .87 & $1.8(8.39)$ & $12.3(17.11)$ & $1.74 \dagger$ \\
\hline
\end{tabular}

Note. ToM $=$ Theory of Mind; SIP $=$ Social Information Processing; TD = Typically Developing, EB = Externalizing Behavior, RES $=$ Social problem-solving task. $\dagger p \leq .10$.

Table 3. Means and standard deviations for both experimental and control EB groups in pre-test session and between-group comparisons

\begin{tabular}{|c|c|c|c|c|c|}
\hline \multirow{3}{*}{ Variables } & & \multicolumn{3}{|c|}{ Pre-test session } & \multirow[b]{3}{*}{$X^{2} / F$} \\
\hline & & Control group & \multirow{2}{*}{$\begin{array}{l}\text { ToM group } \\
M \text { (SD) } \\
n=9\end{array}$} & SIP group & \\
\hline & & $\begin{array}{l}M(\mathrm{SD}) \\
n=9\end{array}$ & & $M$ (SD) & \\
\hline Sex (\% Male) & & 78 & 55 & 100 & $5.56 \dagger$ \\
\hline CA (in months) & & $68.78(17.73)$ & $71.44(11.98)$ & $76.90(11.42)$ & .84 \\
\hline GDA & & $56.78(16.32)$ & $52.36(11.04)$ & $55.93(11.50)$ & .29 \\
\hline VDA & & $48.67(11.50)$ & $48.83(9.67)$ & $56.25(13.74)$ & 1.29 \\
\hline ToM & ToM-emotions & $6.56(2.72)$ & $6.44(2.16)$ & $6.70(1.99)$ & .03 \\
\hline & ToM-beliefs & $3.55(1.13)$ & $3.44(1.29)$ & $3.35(1.33)$ & .06 \\
\hline SIP & RES total & $57.44(23.06)$ & $51.67(13.66)$ & $56.40(18.37)$ & .25 \\
\hline & RES Question 1 & $22.89(6.33)$ & $22.22(4.52)$ & $22.80(4.73)$ & .04 \\
\hline & RES Question 2 & $10.22(3.53)$ & $9.78(3.07)$ & $10.50(3.24)$ & .12 \\
\hline & RES Question 3 & $25.22(23.06)$ & $19.67(9.34)$ & $23.30(11.78)$ & .48 \\
\hline Family measures & Mothers' education $(\max =7)$ & $5.33(1.51)$ & $4(.82)$ & $4(1.73)$ & 1.48 \\
\hline & Fathers' education $(\max =7)$ & $4.67(1.97)$ & $2.5(2.12)$ & $3(1.41)$ & 1.23 \\
\hline
\end{tabular}

Notes. $\mathrm{CA}=$ Chronological Age; GDA $=$ Global Developmental Age; VDA $=$ Verbal Developmental Age, ToM $=$ Theory of Mind; SIP = Social Information Processing; RES = Social problem-solving task. $\dagger p \leq .10$.

Table 4. Means and standard deviations in pre-test, post-test in ToM and SIP measures for both experimental and control EB groups and $t$-test for the pre/post-test difference

\begin{tabular}{|c|c|c|c|c|c|c|c|c|c|c|c|}
\hline \multirow[b]{4}{*}{ ToM-emotions } & \multicolumn{3}{|c|}{$\begin{array}{l}\text { Control group } \\
n=9\end{array}$} & \multicolumn{4}{|l|}{$\begin{array}{l}\text { ToM group } \\
n=9\end{array}$} & \multicolumn{4}{|l|}{$\begin{array}{l}\text { SIP group } \\
n=10\end{array}$} \\
\hline & Pre-test & Post-test & $\triangle$ & Pre-test & Post-test & $\triangle$ & $\begin{array}{l}\text { Partial } \\
\text { Eta }^{2}\end{array}$ & Pre-test & Post-test & $\triangle$ & $\begin{array}{l}\text { Partial } \\
\text { Eta }^{2}\end{array}$ \\
\hline & $M(\mathrm{SD})$ & $M(\mathrm{SD})$ & $t$ & $M(\mathrm{SD})$ & $M(\mathrm{SD})$ & $t$ & & $M(\mathrm{SD})$ & $M(\mathrm{SD})$ & $t$ & \\
\hline & $6.56(2.72)$ & $7.17(2.15)$ & .65 & $6.44(2.16)$ & $8.94(2.74)$ & $1.96 \dagger$ & .32 & $6.70(1.99)$ & $8.15(2.46)$ & $2.00 \dagger$ & .31 \\
\hline Cause & $3.56(1.45)$ & $3.72(1.12)$ & .58 & $3.56(1.68)$ & 4.94 (1.18) & $2.23 \dagger$ & .38 & $3.90(1.43)$ & $4.35(1.60)$ & .83 & \\
\hline Consequence & $3.00(1.70)$ & $3.44(2.14)$ & .47 & 2.89 (1.39) & $4.00(1.73)$ & 1.33 & & $2.80(1.06)$ & $3.80(1.23)$ & $2.18 \dagger$ & .35 \\
\hline ToM-beliefs & $3.55(1.13)$ & $3.39(1.24)$ & -.63 & $3.44(1.29)$ & $4.33(.93)$ & $2.02 \dagger$ & .34 & 3.35 (1.33) & $4.15(.71)$ & $2.39 *$ & .39 \\
\hline RES total & $\begin{array}{l}57.44 \\
(23.06)\end{array}$ & $\begin{array}{l}58.33 \\
(22.53)\end{array}$ & .25 & $\begin{array}{l}51.67 \\
(13.66)\end{array}$ & $\begin{array}{l}70.33 \\
(21.35)\end{array}$ & $2.61^{*}$ & .46 & $\begin{array}{l}56.40 \\
(18.37)\end{array}$ & $\begin{array}{l}71.80 \\
(25.85)\end{array}$ & $2.24^{*}$ & .36 \\
\hline RES Q1 & $\begin{array}{l}22.89 \\
(6.33)\end{array}$ & $\begin{array}{l}23.33 \\
(6.16)\end{array}$ & .45 & $\begin{array}{l}22.22 \\
(4.52)\end{array}$ & $\begin{array}{l}24.89 \\
(3.62)\end{array}$ & $2.00 \dagger$ & .33 & $\begin{array}{l}22.80 \\
(4.73)\end{array}$ & $\begin{array}{l}24.80 \\
(4.34)\end{array}$ & 1.58 & \\
\hline RES Q2 & $\begin{array}{l}10.22 \\
(3.53)\end{array}$ & $\begin{array}{l}10.11 \\
(3.89)\end{array}$ & .36 & $9.78(3.07)$ & $\begin{array}{l}11.67 \\
(3.78)\end{array}$ & $1.96 \dagger$ & .32 & $\begin{array}{l}10.50 \\
(3.24)\end{array}$ & $\begin{array}{l}11.40 \\
(4.74)\end{array}$ & 1.13 & \\
\hline RES Q3 & $\begin{array}{l}25.22 \\
(23.06)\end{array}$ & $\begin{array}{l}23.89 \\
(12.01)\end{array}$ & .68 & $\begin{array}{l}19.67 \\
(9.34)\end{array}$ & $\begin{array}{l}33.78 \\
(15.76)\end{array}$ & $2.37^{*}$ & .41 & $\begin{array}{l}23.30 \\
(11.78)\end{array}$ & $\begin{array}{l}35.60 \\
(17.71)\end{array}$ & $2.27^{*}$ & .36 \\
\hline $\begin{array}{l}\% \text { of wrong/no } \\
\text { justification }\end{array}$ & $\begin{array}{l}33.33 \\
(28.35)\end{array}$ & $\begin{array}{l}34.92 \\
(23.27)\end{array}$ & .37 & $\begin{array}{l}50.79 \\
(18.36)\end{array}$ & $\begin{array}{l}30.16 \\
(22.80)\end{array}$ & $-2.87 *$ & .39 & $\begin{array}{l}44.29 \\
(24.47)\end{array}$ & $\begin{array}{l}25.71 \\
(27.60)\end{array}$ & $-2.86^{*}$ & .48 \\
\hline $\begin{array}{l}\% \text { of descriptive } \\
\text { level }\end{array}$ & $\begin{array}{l}51.59 \\
(24.43)\end{array}$ & $\begin{array}{l}51.59 \\
(14.19)\end{array}$ & .00 & $\begin{array}{l}35.71 \\
(17.49)\end{array}$ & $\begin{array}{l}46.82 \\
(22.33)\end{array}$ & 1.08 & & $\begin{array}{l}37.86 \\
(22.35)\end{array}$ & $\begin{array}{l}44.29 \\
(24.93)\end{array}$ & .76 & \\
\hline $\begin{array}{l}\% \text { of } \\
\text { intersubjective } \\
\text { level }\end{array}$ & $\begin{array}{l}14.28 \\
(18.21)\end{array}$ & $\begin{array}{l}13.49 \\
(14.48)\end{array}$ & .24 & $\begin{array}{l}11.90 \\
(14.28)\end{array}$ & $\begin{array}{l}20.63 \\
(18.01)\end{array}$ & 1.01 & & $\begin{array}{l}17.14 \\
(15.13)\end{array}$ & $\begin{array}{l}22.86 \\
(16.08)\end{array}$ & 1.03 & \\
\hline $\begin{array}{l}\% \text { of conceptual } \\
\text { level }\end{array}$ & $.79(2.38)$ & $.00(.00)$ & 1.00 & $1.59(3.15)$ & $2.38(5.05)$ & .36 & & $.71(2.26)$ & $\begin{array}{l}7.14 \\
(10.10)\end{array}$ & $1.96 \dagger$ & .30 \\
\hline
\end{tabular}

Note. $=\not$ post-test - pre-test difference; ToM $=$ Theory of Mind, SIP = Social Problem-Solving; RES = Social problem-solving task. $\dagger p \leq .10,{ }^{*} p \leq .05$ 


\section{Acknowledgements}

The authors wish to thank David Schultz and Yair Ziv for their materials. We are also grateful to the children, parents, and teachers for their cooperation.

This project was financially supported by a concerted research action on externalizing behavior (Convention ARC 11/16-038) and by Fonds de Soutien Marguerite-Marie Delacroix.

\section{References}

Achenbach, T. M. (1991). Manual for the CBCL/4-18 and 1991 Profile.

Amsterlaw, J., \& Wellman, H. M. (2006). Theories of mind in transition: A microgenetic study of the development of false belief understanding. Journal of Cognition \& Development, 7, 139-172. http://dx.doi.org/10.1207/s15327647jcd0702_1

Appleton, M., \& Reddy, V. (1996). Teaching three year-olds to pass false belief tests: A conversational approach. Social Development, 5, 275-291. http://dx.doi.org/10.1111/j.1467-9507.1996.tb00086.x

Barisnikov, K., Van der Linden, M., \& Hippolyte, L. (2004). Tâche de résolution sociale. Manuel inédit. Genève.

Baurain, C., \& Nader-Grosbois, N. (2013). Theory of Mind, Socio-Emotional Problem-Solving, Socio-Emotional Regulation in Children with Intellectual Disability and in Typically Developing Children. Journal of autism and developmental disorders, 43(5), 1080-1097. https://doi.org/10.1007/s10803-012-1651-4

Bhavnagri, N. P., \& Samuels, B. G. (1996). Children's literature and activities promoting social cognition of peer relationships in preschoolers. early Childhood Research Quarterly, 11, 307-331. http://dx.doi.org/10.1016/S0885-2006(96)90010-1

Blair, R. J. R., \& Coles, M. (2000). Expression recognition and behavioural problems in early adolescence. cognitive development, 15, 421-434. http://dx.doi.org/10.1016/S0885-2014(01)00039-9

Campbell, S. B. (2006). Behaviour problems in preschool children: clinical and developmental issues. New-York: Guilford Press.

Clements, W. A., Rustin, C. L., \& McCallum, S. (2000). Promoting the transition from implicit to explicit understanding: a training study of false belief. Developmental Science, 3(1), 81. https://doi.org/10.1111/1467-7687.00102

Crick, N. R., \& Dodge, K. A. (1994). A review and reformulation of social information-processing mechanisms in children's social adjustment. Psychological Bulletin, 115(1), 74-101. http://dx.doi.org/10.1037/0033-2909.115.1.74

Crick, N. R., \& Dodge, K. A. (1996). Social information-processing mechanisms in reactive and proactive aggression. Child Development, 67, 993-1002. http://dx.doi.org/10.2307/1131875

Cutting, A. L., \& Dunn, J. (1999). Theory of mind, emotion understanding, language, and family background: Individual differences and interrelations. Child Development, 70, 853-865. https://doi.org/10.1111/1467-8624.00061

Deneault, J., \& Ricard, M. (2013). Are emotion and mind understanding differently linked to young children's social adjustment? Relationships between behavioral consequences of emotions, false belief, and SCBE. The journal of Genetic Psychology, 174(1), 88-116. http://dx.doi.org/10.1080/00221325.2011.642028

Denham, S. A., Blair, K. A., DeMulder, E., Levitas, J., Sawyer, K., Auerbach-Major, S., \& Queenan, P. (2003). Preschool emotional competence: Pathway to social competence? Child Development, 74(1), $238-256$. http://dx.doi.org/10.1111/1467-8624.00533

Denham, S. A., \& Burton, R. (2003). Social and emotional prevention and intervention programming for preschoolers. New York: Kluwer-Plenum.

Denham, S. A., Zinsser, K., \& Bailey, C. S. (2011). Emotional intelligence in the first five years of life. . In B. Trembay RE, M., Peters RDeV. (Ed.), Encyclopedia on Early Childhood Development (Vol. 1-7). Montreal, Quebec: Centre of Excellence for Early Childhood Development and Strategic Knowledge Cluster on Early Child Development.

Dodge, K. A., \& Crick, N. R. (1990). Social information-processing bases of aggressive behaviour in children Personality and Social Psychology Bulletin, 16, 8-22. http://dx.doi.org/10.1177/0146167290161002

Dodge, K. A., Lansford, J. E., Burks, V. S., Bates, J. E., Pettit, G. S., Fontaine, R., \& Price, J. M. (2003). Peer rejection and social information-processing factors in the development of aggressive behavior problems in children. Child Development, 74(2), 374-393. http://dx.doi.org/10.1111/1467-8624.7402004

Dodge, K. A., \& Pettit, G. S. (2003). A biopsychosocial model of the development of chronic conduct problems in adolescence. Developmental Psychology, 39(2), 349-371. http://dx.doi.org/10.1037/0012-1649.39.2.349 
Eisenberg, N., Cumberland, A., \& Spinrad, T. L. (1998). Parental socialization of emotion. Psychological inquiry, 9(4), 241-273. https://doi.org/10.1207/s15327965pli0904_1

Eisenberg, N., Fabes, R. A., Shepard, S. A., Murphy, B. C., Guthrie, I. K., Jones, S., ... Maszk, P. (1997). Contemporaneous and longitudinal prediction of children's social functioning from regulation and emotionality. Child Development, 68, 642-664. http://dx.doi.org/10.2307/1132116

Fahie, C. M., \& Symons, D. K. (2003). Executive functioning and theory of mind in children clinically referred for attention and behavior problems. Applied Developmental Psychology, 24, 51-73. http://dx.doi.org/10.1016/S0193-3973

Faivre, L. F., Rossignol, S. A., Serpa, S. R., Knauer, D., Espasa, F. P., \& Robert-Tissot, C. (2005). Troubles du comportement entre 18 et 36 mois: symptomatologie et psychopathologie associées. Neuropsychiatrie de l'enfance et de l'adolescence, 53, 176-185. https://doi.org/10.1016/j.neurenf.2005.04.001

Flavell, J. H. (1986). The development of children's knowledge about the appearance-reality distinction. American Psychologist, 41(4), 418-425. https://doi.org/10.1037/0003-066x.41.4.418

Flavell, J. H. (1999). Cognitive development: Children's knowledge about the mind. Annual Review of Psychology, 50, 21-45. http://dx.doi.org/10.1146/annurev.psych.50.1.21

Flavell, J. H., Everett, B. A., Croft, K., \& Flavell, E. R. (1981). Young children's knowledge about visual perception: Further evidence for the level 1-level 2 distinctions. Developmental Psychology, 17(1), 99-103. http://dx.doi.org/10.1037/0012-1649.17.1.99

Gevers, C., Clifford, P., Mager, M., \& Boer, F. (2006). Brief Report: A Theory-of-Mind-bases Social-Cognition Training Program for School-Aged Children with Pervasive Developmental Disorders: An Open Study of its Effectiveness. Journal of autism and developmental disorders, 36(4), 567-571. http://dx.doi.org/10.1007/s10803-006-0095-0

Hadwin, J., Baron-Cohen, S., Howlin, P., \& Hill, K. (1996). Can we teach with autism to understand emotions, belief, or pretence? Development and Psychopathology, 8, 345-365. http://dx.doi.org/10.1017/S0954579400007136

Hippolyte, L., Iglesias, K., Van der Linden, M., \& Barisnikov, K. (2010). Social reasoning skills in adults with Down syndrome: the role of language, executive functions and socio-emotional behaviour. Journal of Intellectual Disability Research, 54(8), 714-726. https://doi.org/10.1111/j.1365-2788.2010.01299.x

Houssa, M., \& Nader-Grosbois, N. (2016). Could Social Cognition Training Reduce Externalizing Behaviors and Social Maladjustment in Preschoolers. Journal of Psychological Abnormalities, S1(5). https://doi.org/10.4172/jpab.S1-005

Houssa, M., Nader-Grosbois, N., \& Jacobs, E. (2014). Experimental study of short term training in social cognition in typically developing preschoolers. Journal of Education and Training Studies, 2(1), 139-154.

Howlin, P., Baron-Cohen, S., \& Hadwin, J. (2011). Apprendre aux enfants autistes à comprendre la pensée des autres.

Hughes, C., Dunn, J., \& White, A. (1998). Trick or treat? : Uneven understanding of mind and emotion and executive dysfunction in hard-to-manage preschoolers (English). Journal of child psychology and psychiatry and allied disciplines (Print), 39(7), 981-994. http://dx.doi.org/10.1111/1469-7610.00401

Hutchins, T. L., \& Prelock, P. A. (2006). Using social stories and comic strip conversations to promote socially valid outcomes for children with autism. Paper presented at the Seminars in Speech and Language. https://doi.org/10.1055/s-2006-932438

Hutchins, T. L., Prelock, P. A., \& Chace, W. (2008). Test-retest reliability of a theory of mind task battery for children with autism spectrum disorders. Focus on autism and other developmental disabilities, 23(4), 195-206. http://dx.doi.org/10.1177/1088357608322998

Juarez, M. I., Juarez, S. A., \& Monfort, M. (2009). Mental Simil (Entha ed.).

Kloo, D., \& Perner, J. (2003). Training Transfer Between Card Sorting and False Belief Understanding: Helping Children

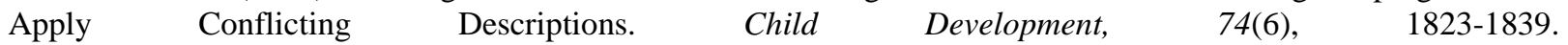
https://doi.org/10.1046/j.1467-8624.2003.00640.x

Lansford, J. E., Malone, P. S., Stevens, K. I., Dodge, K. A., Bates, J. E., \& Pettit, G. S. (2006). Developmental trajectories of externalizing and internalizing behaviors: Factors underlying resilience in physically abused children. Development and Psychopathology, 18(01), 35-55. https://doi.org/10.1017/S0954579406060032

Li, J., Fraser, M. W., \& Wike, T. L. (2013). Promoting social competence and preventing childhood aggression: A framework for applying social information processing theory in intervention research. Aggression and Violent Behavior, 18(3), 357-364. 
Marsh, A. A., \& Blair, R. J. R. (2008). Deficits in facial affect recognition among antisocial populations : A meta-analysis. Neuroscience and Biobehavioral Reviews, 32, 454-465. http://dx.doi.org/10.1016/j.neubiorev.2007.08.003

Melot, A., \& Angeard, N. (2003). Theory of mind: is training contagious? Developmental Science, 6(2), 178-184. http://dx.doi.org/10.1111/1467-7687.00269

Nader-Grosbois, N. (2011). La théorie de l'esprit: entre cognition, émotion et adaptation sociale. Bruxelles: De Boeck. https://doi.org/10.3917/dbu.nader.2011.01.0093

Nader-Grosbois, N., Houssa, M., \& Mazzone, S. (2013). How could theory of mind contribute to the differentiation of social adjustment profiles of children with externalizing behavior disorders and children with intellectual disabilities? Research in Developmental Disabilities, 34, 2642-2660. http://dx.doi.org/10.1016/j.ridd.2013.05.010

Nader-Grosbois, N., \& Thirion-Marissiaux, A. F. (2011). Evaluer la compréhension des états mentaux «émotions »et « croyances ». In N. Nader-Grosbois (Ed.), Théorie de l'esprit : Entre cognition, émotion et adaptation sociale chez des personnes typiques et atypiques. Bruxelles: De Boeck.

Oswald, D. P., \& Ollendick, T. H. (1989). Role taking and social competence in autism and mental retardation. Journal of autism and developmental disorders, 19(1), 119-127. http://dx.doi.org/10.1007/BF02212723

Perner, J., Leekam, H., \& Wimmer, H. (1987). Three-year-olds' difficulty with false belief: The case for a conceptual deficit. British Journal of Developmental Psychology, 5, 125-137. http://dx.doi.org/10.1111/j.2044-835X.1987.tb01048.x

Perron-Borelli, M. (1996). Echelles Différentielles d'Efficiences Intellectuelles. Forme révisée (EDEI-R). Paris: Editions et Applications Psychologiques.

Pettit, G. S., Dodge, K. A., \& Brown, M. M. (1988). Early family experience, social problem solving patterns, and children's social competence. Child Development, 59, 107-120. http://dx.doi.org/10.2307/1130393

Renouf, A., Brendgen, M., Parent, S., Vitaro, F., David Zelazo, P., Boivin, M., ... Séguin, J. R. (2010). Relations between theory of mind and indirect and physical aggression in kindergarten: Evidence of the moderating role of prosocial behaviors. Social Development, 19(3), 535-555. https://doi.org/10.1111/j.1467-9507.2009.00552.x

Repacholi, B., Slaughter, V., Pritchard, M., \& Gibbs, V. (2003). Theory of Mind, machiavellianism and social functioning in childhood. In B. Repacholi \& V. Slaughter (Eds.), Individual differences in theory of mind: Implications for typical and atypical development (pp. 67-97). New York: Psychology Press.

Roskam, I., Meunier, J. C., Stievenart, M., \& Noël, M. P. (2013). When there seem to be no predetermining factors: Early child and proximal family risk predicting externalizing behavior in young children incurring no distal family risk. Research in Developmental Disabilities, 34(1), 627-639. https://doi.org/10.1016/j.ridd.2012.10.002

Runions, K. C., \& Keating, D. P. (2007). Young children's Social Information Processing: Family antecedents and behavioral correlates. Developmental Psychology, 43(4), 838-849. https://doi.org/10.1037/0012-1649.43.4.838

Schultz, D., Ambike, A., Logie, S. K., Bohner, K. E., Stapleton, L. M., VanderWalde, H., ... Betkowski, J. A. (2010). Assessment of Social Information Processing in early childhood: Development and initial validation of the Schultz Test of Emotion Processing-Preliminary version. Journal of Abnormal Child Psychology, 38, 601-613. doi: http://dx.doi.org/10.1007/s10802-010-9390-5

Shure, M. B., \& Spivack, G. (1982). Interpersonal problem-solving in young children: A cognitive approach to prevention. American Journal of Community Psychology, 10(3), 341-356. http://dx.doi.org/10.1007/BF00896500

Speltz, M. L., DeKlyen, M., Calderon, R., Greenberg, M. T., \& Fisher, P. A. (1999). Neuropsychological characteristics and test behaviors of boys with early onset conduct problems. Journal of Abnormal Psychology, 108(2), 315-325. https://doi.org/10.1037/0021-843x.108.2.315

Sweettenham, J. S. (1996). Can children with autism be taught to understand false belief using computers? Journal of child psychology and psychiatry, 37(2), 157-165. https://doi.org/10.1111/j.1469-7610.1996.tb01387.x

Van Nieuwenhuijzen, M., \& Vriens, A. (2012). (Social) Cognitive skills and social information processing in children with mild to borderline intellectual disabilities. Research in Developmental Disabilities, 33(2), 426-434. https://doi.org/10.1016/j.ridd.2011.09.025

Walker, S. (2005). Gender Differences in the Relationship Between Young Children's Peer-Related Social Competence and Individual Differences in Theory of Mind. Journal of Genetic Psychology, 166(3), 297-312. 10.3200/gntp.166.3.297-312 
Webster-Stratton, C., Reid, J., \& Beauchaine, T. (2011). Combining parent and child training for young children with ADHD. Journal of Clinical Child \& Adolescent Psychology, 40(2), 191-203. https://doi.org/10.1080/15374416.2011.546044

Wellman, H. M. (1991). From desires to beliefs: acquisition of a theory of mind. In A. Whiten (Ed.), Natural theories of mind (pp. 19-38). Cambridge, MA: Basil Blackwell.

Wimmer, H., \& Perner, J. (1983). Beliefs about beliefs: Representation and constraining function of wrong beliefs in young children's understanding of deception. Cognition, 13, 103-128. https://doi.org/10.1016/0010-0277(83)90004-5

Yeates, K. O., Dennis, M., Rubin, K. H., Taylor, H. G., Bigler, E. D., Gerhardt, C. A., \& Vannatta, K. (2007). Social outcomes in childhood brain disorder: A heuristic integration of social neuroscience and developmental psychology. Psychological Bulletin, 133, 535-556. http://dx.doi.org/10.1037/0033-2909.133.3.535

Yoon, J., Hughes, J., Gaur, A., \& Thompson, B. (1999). Social cognition in aggressive children: A metaanalytic review. Cognitive and Behavioral Practice, 6(4), 320-331. https://doi.org/10.1016/S1077-7229(99)80051-0

Ziv, Y., \& Sorongon, A. (2011). Social information processing in preschool children: Relations to sociodemographic risk and problem behavior. Journal of Experimental Child Psychology, 109, 412-429.

http://dx.doi.org/10.1016/j.jecp.2011.02.009

\section{Copyrights}

Copyright for this article is retained by the author(s), with first publication rights granted to the journal.

This is an open-access article distributed under the terms and conditions of the Creative Commons Attribution license which permits unrestricted use, distribution, and reproduction in any medium, provided the original work is properly cited. 